\title{
Em defesa da moral cristã? \\ Fundamentos e justificativas da bancada evangélica nos projetos de lei anti aborto
}

\author{
Naiana Zaiden Rezende Souza
}

\section{RESUMO}

Desde a redemocratização em 1988 até as eleições mais recentes, segmentos religiosos vêm ampliando sua ação no meio político com o propósito de restaurar na sociedade brasileira a moral e os bons costumes cristãos. A atuação dos políticos religiosos, principalmente dos integrantes da Frente Parlamentar Evangélica, no Congresso Nacional, vem chamando a atenção da população e da mídia pelos projetos de leis e propostas de emendas constitucionais polêmicos. Dentre estas proposições, as que mais se destacaram nos últimos tempos foram as pautas referentes ao movimento LGBTTQ e às causas feministas, mais precisamente, os projetos que visam retirar direitos constitucionais e infraconstitucionais já garantidos, como o casamento e o aborto. Diante dessa realidade, o presente trabalho propõe-se a debater os projetos de leis de parlamentares da bancada evangélica que tratem da interrupção voluntária da gravidez, trazendo suas justificativas e fundamentos, com o intuito de discutir se o discurso religioso ainda é utilizado como motivação política para a proibição do aborto. Para tanto, foi feita uma revisão bibliográfica da temática analisando os projetos de leis previamente selecionados, bem como autores consagrados que tratam sobre a atuação evangélica na política e também das questões de aborto e direitos humanos pertinentes ao estudo proposto. Após a pesquisa, percebeu-se que o discurso religioso pró vida ainda se faz presente nas propostas legislativas, mas sempre concatenado com argumentos de outra natureza (científico e social, por exemplo) para legitimar e legalizar os projetos de leis ou emenda constitucional.

Palavras-chave: bancada evangélica, discurso religioso, aborto, direitos reprodutivos e sexuais.

\section{DEFENDING CHRISTIAN MORAL? MOTIFS AND FUNDAMENTS PRESENTED IN ANTI ABORTION LAW PROJECTS OF THE EVANGELICAL FRONT}

\section{ABSTRACT}

Since the re-democratization in 1988 until the most recent elections, religious segments have been expanding their action into the political sphere with the purpose of restoring in Brazilian society moral and good Christian customs. The work of religious politicians, especially members of the Evangelical Parliamentary Front, in the National Congress, has drawn the attention of the population and the media to the draft laws and proposals for controversial constitutional amendments. Among 
these propositions, the most relevant ones in recent times were the guidelines referring to the LGBTTQ movement and to feminist causes, more precisely, the projects aimed at the withdrawal of constitutional and infra-constitutional rights already guaranteed, such as marriage and abortion. In the face of this reality, the present work proposes to debate the bills of congressmen from the evangelical group that deals with the voluntary interruption of pregnancy, bringing its justifications and foundations, in order to discuss whether religious discourse is still used as a political motivation for the prohibition of abortion. For this purpose, a bibliographical review of the theme was carried out analyzing the draft laws previously selected, as well as established authors dealing with the evangelical work in politics, as well as abortion and human rights issues pertinent to the proposed study. After the research, it was noticed that the pro-life religious discourse is still present in legislative proposals, but always linked with arguments of another nature (scientific and social, for example) to legitimize and legalize draft laws or constitutional amendment.

Keywords: evangelical front, religious discourse, abortion, reproductive and sexual rights.

\section{INTRODUÇÃO}

Questões em torno do aborto, proteção à vida e direitos sexuais e reprodutivos das mulheres estão cada vez mais tendo espaço no debate social e político. Fatos recentes no Brasil e no mundo demonstram que as mulheres estão buscando meios legais para garantirem sua autodeterminação enquanto que, por outro lado, atores religiosos usam de suas influências e posições parlamentares para defenderem a vida. Desde a recente redemocratização brasileira as bancadas religiosas vêm conquistando mais cadeiras no Congresso Nacional fator que lhes dá mais força para defender suas visões e aprovar/ modificar leis e até mesmo a própria Constituição
Federal. Dentre essas bancadas religiosas, a Frente Parlamentar Evangélica vem sendo destaque nas mídias e redes sociais por muitas posições polêmicas que seus integrantes defendem. Seja em defesa à vida ou pela restauração no Brasil da moral e dos bons costumes cristãos, os parlamentares evangélicos vêm-se na missão de proteger a família dos males modernos que a ameaçam.

Neste cenário de caos social, a temática do aborto é um prenúncio real da desordem social. O Código Penal de 1940 criminaliza o aborto punindo tanto a mãe quanto qualquer um que a ajudar a interromper a gravidez. Mas, prevê dois casos específicos em que tal prática não é tipificada: quando o procedimento for necessário para salvaguardar a vida da mulher e quando a gestação for em decorrência de estupro. Contudo, nos últimos cinco anos o Supremo Tribunal Federal tem permitido o aborto em vários outros casos, fator que gerou uma reação da bancada evangélica que, em resposta, propôs leis, emendas à constituição e promoveu debates no Congresso Nacional a fim de conscientizar a população e os demais parlamentares sobre a necessidade da defesa à vida em qualquer estágio.

Natentativadecaptar seos discursos contrários ao aborto são estritamente religiosos ou também embasados em motivos científicos e jurídicos, trazemos à baila os projetos de leis 460/2016 e 461/2016 do Senado Federal e 8116/2014, $5069 / 2013,1545 / 2011,7443 / 2006$, e 5166/2005, todos da Câmara dos Deputados; bem como as Propostas de Emenda à Constituição: 58/2011 e 181/2015 que versam sobre a criminalização da interrupção voluntária da gravidez ou sobre a proteção à vida. A prática metodológica utilizada neste trabalho compreende-se no estudo bibliográfico e documental de propostas legislativas que versem sobre o tema, bem como análise de jurisprudência do Supremo Tribunal Federal tratando sobre o aborto, valendo-se também do uso de sítios da Internet, empregados modernamente em pesquisas, assim como livros, artigos, relatórios e notícias para complementar o estudo. 
1. O BRASIL LAICO/SECULAR E A BANCADA EVANGÉLICA

Entender a presença e atuação dessa frente parlamentar no espaço público demanda, inicialmente, fazer um pequeno retrocesso nas ideias de laicidade e secularização, trazendo seus significados e qual a situação de ambos no cenário brasileiro. "O termo secularização é pensado na perspectiva da redução da presença e influência religiosa na sociedade em geral e laicidade diz respeito ao processo mais específico que envolve as relações entre religião e Estado em interface com a esfera política" (SOFIATI, 2015, pg. 328). Desde a chegada portuguesa até 1889 , o Brasil teve como religião oficial a Católica, sendo que a todas as outras era proibido o culto no espaço público.

Com a Proclamação da República em 15 de novembro de 1889 e com a segunda Constituição brasileira em vigor ${ }^{1}$, no ano de 1891, oficialmente o Estado tornou-se laico. No entanto, a questão da liberdade religiosa só foi amplamente discutida e revista com o advento da Constituição Federal de 1988, que consolidava os princípios e garantias fundamentais dos indivíduos e o Estado Democrático de Direito. Então, o Estado era declaradamente laico e a toda e qualquer religião era permitido professar seu culto e liturgia livremente. Atualmente, a liberdade religiosa está prevista no artigo $5^{\circ}$, inciso VI, tendo como base três pontos cruciais: liberdade de crença, liberdade de organização e liberdade de culto. Segundo tal artigo, é inviolável a liberdade de consciência e de crença, sendo assegurado o livre exercício dos cultos religiosos e garantida, na forma da lei, a proteção aos locais de culto e às suas liturgias (BRASIL, 1988).

No âmbito social, o Brasil também se tornou secular na medida em que a Igreja Católica perdeu seu posto de religião oficial e, junto a isso, alguns privilégios ligados ao casamento, sepultamento e costumes culturais. Sofiati
(2015), bem aponta a visão de Lísis Negrão de que apesar de as instituições Igreja e Estado estarem separadas, o povo ainda continua sob o encantamento de uma cultura religiosa. Neste mesmo sentido, Berger (2001) pondera que a religião perdeu o grande poder de influência que tinha no meio social, porém, suas crenças e práticas continuaram vivas no cotidiano das pessoas. Assim, o autor afirma que "O mundo de hoje é tão ferozmente religioso quanto antes" (Berger, 2001, p. 10). Esta frase de Peter Berger não poderia estar melhor contextualizada diante dos exemplos atuais no país. No Brasil, a Bancada Evangélica e seu conservadorismo moral legisla a favor de suas crenças e contra vários direitos e garantias fundamentais das mulheres e da população LGBTT, já previstos em leis existentes ou mesmo salvaguardados pelo STF e por Tratados Internacionais de Direitos Humanos.

\begin{abstract}
“Como destaca Enzo Pace (2015, p. 77), [...] o panorama contemporâneo mostra-nos o insurgir de movimentos radicais de inspiração religiosa [...] que pretendem que as leis dos homens (dos Parlamentos) reflitam a Lei de Deus". Esta afirmação pode ser exemplificada nos recentes casos de disputas entre setores da sociedade civil, notadamente da comunidade LGBTT e do movimento feminista com a bancada evangélica do Congresso Nacional. Demandas em torno de questões que envolvem leis concernente aos interesses de grupos homoafetivos e direitos reprodutivos têm sido impedidas de avançar por conta da ação de parlamentares ligados às igrejas pentecostalizadas". (SOFIATI, 2015, pg. 340)
\end{abstract}

Após a redemocratização, em 1988, muitos movimentos subjugados emergiram para reclamarem um espaço no contexto público, sendo este cenário um dos fatores responsáveis pelo avanço do pluralismo religioso e, nesse caso, "a principal forma de influência da religião no Estado é por meio da ação política a partir das

1 A primeira Constituição Brasileiro é de 1824, sendo outorgada por Dom Pedro I, e previa a Igreja Católica Apostólica Romana como a oficial. 
regras da democracia" (SOFIATI, 2015, pg. 344). Durante séculos o catolicismo foi hegemônico no espaço público, e, ainda hoje detém maior parte dessa influência juntamente com a ação política coordenada dos pentecostais demonstrando que “a religião não perdeu sua influência e continua atuante nas esferas sociais [...], inclusive naquelas que definem os rumos do país, como é o caso do Estado" (SOFIATI, 2015, pg. 336). Magali do Nascimento Cunha (2016) refere-se ao termo "evangélico" como "todos os cristãos não católicos ou ortodoxos que compõem o campo religioso brasileiro" (pg.148), sendo identificados nos estudos de religião por quatro características: "uma predominante leitura fundamentalista do texto sagrado cristão, a Bíblia; ênfase na piedade pessoal na busca da salvação da alma” (pg. 149) além de "frequentes posturas de rejeição das manifestações culturais não cristãs do país e um isolamento das demandas sociais (resultante da espiritualização das questões da existência individual e social), entre elas a participação política” (pg. 149).

A Constituição Democrática permitiu aos evangélicos a percepção de uma oportunidade de sair do estado de invisibilidade, reclamando o acesso à esfera pública institucional que outros setores emergentes começavam a ter e que a Igreja Católica já possuía, além da emergência de uma orientação doutrinária interna, que apontava o ingresso na esfera pública como caminho para a saída da condição de minoria política e culturalmente subalternizada (MACHADO e BURITY 2014). Nesse contexto de representatividade evangélica na política brasileira, surge a Frente Parlamentar Evangélica, "uma associação civil, de natureza não governamental, constituída no âmbito do Congresso Nacional, integrada por Deputados Federais e Senadores" (SCHUCK, 2013, p. 04).
Após as eleições nacionais de 2014, a bancada evangélica passou a ser constituída por 74 deputados, sendo 35 novos e 39 reeleitos, além de 03 Senadores dos mais variados partidos políticos (PMDB, PSDB, PRB, DEM, PT, PV, PDT, PRB, $\mathrm{PTB}, \mathrm{PR}, \mathrm{PP}, \mathrm{PMN})^{2}$, sendo seus integrantes, em sua maioria, membros do Partido Social Cristão (PSC), ligados à Igreja Universal do Reino de Deus.

Esta bancada, apesar de recente, ganhou bastante visibilidade devido a alguns projetos de lei apresentados por seus integrantes, tais como o Estatuto da Família, a Cura Gay e o Estatuto do Nascituro. Todos justificados pela necessidade de reintegrar a moral cristã numa sociedade desvirtuada e promíscua. Nessa linha, a bancada evangélica tomou forma tendo como objetivo principal defender a família tradicional brasileira e a vida. Assim, a família brasileira seria aquela substancialmente patriarcal, formada por um casal heterossexual e seus filhos, sendo o homem o chefe de família que sustenta a casa, e a mulher o ser reprodutivo responsável por gerar a vida (sendo esta protegida desde a concepção).

É claro que estas questões morais não são exclusivamente tratadas pelos parlamentares evangélicos. Vários outros projetos de leis e ações judiciais visaram estabelecer a ilegalidade da união homoafetiva, bem como a proteção da vida contra o aborto, tendo inclusive uma atuação direta de instituições religiosas (como a igreja católica) nestes processos ${ }^{3}$. A maioria dessas proposições tinham o intuito de frear a reação que os movimentos feministas e LGBTTs geraram na sociedade após os anos 80 , e, "talvez pela primeira vez, a sexualidade se tornou uma verdadeira questão política de primeira linha, com a Nova Direita identificando o "declínio da família”, o feminismo e a nova militância homossexual como potentes símbolos do declínio congresso-psc-lidera-em-numero-de-parlamentares

3 Em 2004 o Supremo Tribunal Federal rejeitou o pedido da Confederação Nacional dos Bispos do Brasil (CNBB) de agir como "amicus curiae" e manifestar (contrariamente) na ação que decidiu sobre o direito de gestantes interromperem a gravidez em casos de feto anencefálico (http://www.conjur.com.br/2004-jun-24/marco_aurelio_rejeita_cnbb_amicus_ curiae_processo). 
nacional" (WEEKS, 2007, pg. 54).

OBrasil, por sua história política, só foi ter uma abertura maior para os assuntos de sexualidade no século XXI e, desde então, os partidos e políticos mais conservadores (geralmente ligados às doutrinas cristãs) vem batalhando contra grupos e instituições que trabalham em prol dos Direitos Humanos ligados à sexualidade e à autonomia das mulheres. Tanto é assim que os parlamentares integrantes dos grupos religiosos passaram a apresentar novos projetos que tratam dessa temática, alguns escancaradamente contrários às decisões já consolidadas do STF ou STJ ou mesmo contra leis que assegurem os direitos sexuais e reprodutivos das mulheres, com objetivo de "impedir a implementação de serviços de aborto dentro dos limites permitidos pela lei, ou para judicializar casos de aborto não puníveis" (RUIBAL, 2014, pg. 116). E, nosso objetivo aqui é apontar quais são os principais argumentos utilizados pelos autores dessas proposições a fim de identificar se há ou não um discurso de natureza confessional contra o aborto e em favor da vida.

2. EM PROL DA VIDA E DA FAMÍLIA: O DISCURSO DA BANCADA EVANGÉLICA.

\section{A 55a legislatura (2014-2018) formou o} Congresso mais conservador que o Brasil já teve desde a redemocratização em 1988 e isto tem levantado várias questões quanto à atuação de grupos religiosos que legislam conforme suas crenças e, por vezes, contrariam normas que asseguram direitos de grupos minoritários. O aborto é uma questão de saúde pública e não só o Legislativo, mas também os Poderes Executivo e Judiciário se preocupam com a temática diante da realidade nacional. A discussão do tema tornase ainda mais importante quando analisamos os dados obtidos em estudos sobre a temática, apontando que mesmo sendo considerado um delito, o aborto clandestino ainda é uma prática comum entre as brasileiras. Os resultados da Pesquisa Nacional do Aborto de 2016 (DINIZ, MADEIRO, MEDEIROS, 2016), feita entre mulheres de 18 a 39 anos, demonstrou que $13 \%$ das entrevistadas já fez ao menos 01 aborto no decorrer da vida. Se considerar a faixa etária de 38 e 39 anos a taxa sobe a quase 19\%. Assim, em 2016 tínhamos o total estimado de 37.287.746 brasileiras entre 18 e 39 anos. Extrapolando-se a partir das taxas de aborto de alfabetizadas urbanas (13\%), têm-se o incrível número de 4,7 milhões de mulheres que até 2016 já abortaram ao menos $1 \mathrm{vez}$ (DINIZ, MADEIRO, MEDEIROS, 2016).

Quase metade dos casos registrados de interrupção voluntária da gravidez foi realizada em casa com uso de medicamentos e $48 \%$ das mulheres entrevistadas precisaram ser internadas, seja para proceder com o aborto seguro ou em decorrência de complicações advindas de um aborto inseguro (DINIZ, MADEIRO, MEDEIROS, 2016). As consequências de um aborto inseguro são várias: dano psicológico, infecção de trato genital, sequelas temporárias e permanentes no sistema reprodutivo ou até mesmo a morte. O aborto acontece com maior frequência entre mulheres com baixo grau de informação e escolaridade, sendo que $23 \%$ das brasileiras que abortaram estudaram até o ensino fundamental e $12 \%$ até o ensino médio. As taxas de aborto são maiores dentre as mulheres nãobrancas (pretas/pardas), com mais de um filho nascido vivo, casadas ou em união estável e, por isso, a maioria das brasileiras que morrem em decorrência do aborto ilegal são as negras. (SANTOS, ANJOS, et. al, 2013).

Isto ocorre, provavelmente, por conta do ambiente violento e precário que essas mulheres estão inseridas, bem como em decorrência da falta de acesso a métodos contraceptivos. Ademais, este dado também demonstra a ineficácia do dispositivo que criminaliza o aborto haja vista que aquelas que têm condições de arcarem com um aborto seguro na rede privada assim o fazem, enquanto que as mulheres sem condições financeiras para tal, e sem respaldo do sistema público de saúde, procuram métodos clandestinos e perigosos para interromperem uma gravidez indesejada, colocando suas vidas em risco. No debate sobre aborto temos, de um lado, ativistas, organizações ligadas aos Direitos Humanos, lideranças políticas e grupos feministas 
que defendem a sua descriminalização e, de outro, há instituições religiosas, grupos políticos de viés religioso (principalmente os evangélicos e católicos) e parlamentares conservadores que nem sempre estão inseridos nas bancadas religiosas mas que defendem a família e a vida.

É possível identificar quatro discursos que podem ser encontrados nos projetos (favoráveis ou não) tratando sobre a interrupção voluntária da gravidez. O primeiro é a postura totalmente intransigente que visa defender a vida desde sua concepção e, para tanto, propõe a modificação das leis existentes a fim de criminalizar todo tipo de aborto. Um segundo posicionamento, também contrário à interrupção voluntária da gravidez, defende que a vida deve ser protegida, mas, em alguns casos, é aceitável o aborto pelo bem da mulher. Por outro lado, temos a postura legalista daqueles que defendem que o aborto deve ser liberado em qualquer situação, como forma de afirmação dos direitos reprodutivos e sexuais das mulheres. Por fim, Gonçalves (2016) ainda identifica um quarto discurso possível: a posição dúbia dos parlamentares que "não emitem um parecer concreto sobre o aborto e (ou) que durante suas falas manifestam dúvidas" (pg.181).

Vejamos, então os projetos selecionados que abordam a interrupção voluntária da gravidez, e seus mais variados argumentos. Para tratarmos dessas propostas, optamos por dividir em dois tópicos. O primeiro discutirá os projetos apresentados que defendem a incondicional proteção da vida (desde a sua concepção) e o segundo abordará as proposições (e suas justificativas) que versem sobre a criminalização (tipificação, punição e penas) da interrupção voluntária da gravidez.

\subsection{Por Deus, pela vida e pela família?}

A discussão em torno do aborto gira ao redor de duas questões principais. Primeiro: quando inicia a vida? Segundo, tem a mulher o direito de interromper a gravidez por vontade própria? Bem, o argumento daquelas pessoas que defendem que a vida passa a existir a partir da fecundação do óvulo pelo espermatozoide geralmente baseiase em crenças religiosas (e inclusive utilizado para protestar contra os tratamentos com células tronco). Por outro lado, temos o argumento científico de que a vida só passa a existir a partir das atividades cerebrais, depois do $2^{\circ}$ mês de gestação. Dentro dessa discussão trazemos os projetos de lei $8116 / 2014$ e 5166/2005, todos da Câmara dos Deputados, bem como as PEC's 58/2011 e 181/2015. As propostas de Emenda à Constituição 58 e 181, apesar de originalmente não terem sido apresentadas por integrantes da Bancada Evangélica, sofreram importantes alterações através da ação desse grupo. Ambas atualmente tramitam em conjunto e foram apelidadas de "PEC Cavalo de Troia" por ativistas que lutam pelos direitos sexuais e reprodutivos das mulheres ${ }^{4}$.

As duas preposições nasceram com uma boa intenção, qual seja, estender os direitos de licença maternidade para as mães de filhos pré-maturos. Entretanto, ao longo de sua tramitação foram sofrendo importantes modificações. A principal delas foi apresentada pelo relator deputado Jorge Mudalen, integrante da Bancada Evangélica, inserindo o dispositivo que trata de proteção à vida e à dignidade da pessoa humana desde a concepção. Este trecho revogaria demais leis infraconstitucionais que permitem o aborto em casos específicos (como no caso de estupro, por exemplo).

O deputado, em seu relatório, usou como principal justificativa para a inserção deste dispositivo a necessidade de frear o ativismo judicial do Supremo Tribunal Federal no que concerne ao direito à vida e ao aborto, alegando que cabe somente ao congresso decidir sobre tal matéria, sendo que nenhuma sentença pode valer-se da vontade de uma pessoa não eleita para "estar acima da lei". Afirmou, ainda, que o aborto vem sendo inserido na sociedade por meio 
desse ativismo, considerando tal prática como um direito unilateral das mulheres que deve ser discutido por todos e não simplesmente imposto. Além disso, argumentou que a opinião religiosa é importante na discussão sobre o aborto e, por muitas vezes, ela concorda com argumentos de natureza sociológica, filosófica e até científica, não devendo ser descartada e nem excluída do debate. Por fim, ao propor a modificação do dispositivo, inserindo a defesa à vida desde a concepção, o deputado Mudalen justificou que a proteção da vida prematuramente só faz sentido se também for garantida a sua proteção no âmbito uterino, isto é, desde a concepção, haja vista que o feto também tem direitos e sua dignidade humana deve ser respeitada.

As propostas de Emenda à Constituição, em seu formato original, foram aprovadas pelo Senado e, após a proposição de modificação do texto, ela vem sendo bastante debatida na Câmara, estado atualmente nas mãos de uma comissão criada especialmente para discutir essa matéria. A preocupação das ativistas que defendem os direitos sexuais e reprodutivos femininos é sólida pois as alterações ocasionam um profundo retrocesso dos direitos e garantias individuais.

O PL 8116/2014, de autoria dos deputados Alberto Filho, Arolde de Oliveira e Aníbal Gomes trata sobre os direitos do feto, tendo sido apensando ao projeto do "Estatuto do nascituro" (PL 478/2007, de autoria dos deputados Luiz Bassuma e Miguel Martini). Estas propostas de lei visam proteger a vida intrauterina, não permitindo o aborto nem em casos de deficiência física ou mental ou mesmo em decorrência da probabilidade de sobrevida, além de incluírem o aborto no rol de crimes hediondos e implementar a pensão alimentícia, no valor de 1 salário mínimo, para a criança concebida em um ato de violência sexual, devendo ser paga desde o nascimento até a maioridade civil (18 anos).

Esta pensão, apelidada de "bolsa estupro", vem sendo duramente criticada por juristas e militantes por ser uma violação aos direitos das mulheres e um grande desrespeito de sua autonomia. O Estado, ao invés de assegurar às brasileiras o direito à saúde e dignidade para que decida se quer ou não proceder com uma gravidez indesejada, quer simplesmente tirá-las a opção de minimizar seu sofrimento após terem vivenciado um ato tão cruel e violento. A quantia deverá ser paga pelo estuprador, caso ele tenha condição, ou pelo Governo, quando o estuprador não tiver meio de arcar com essa responsabilidade. O Projeto, ao fazer isso, está dando ao homem o status privilegiado de Pai, obrigando a criança e a mãe a terem uma relação de proximidade com o criminoso, fator que praticamente legitima a violência sexual como mais uma maneira de formar-se uma família. A legislação brasileira que trata dos direitos das mulheres já é bastante criticada por órgãos internacionais devido ao seu caráter conservador, retrógrado e discriminatório, imagine se retroceder ainda mais para obrigar às mulheres estupradas ou com risco de vida de manterem suas gestações. Neste sentido vem sendo importante o ativismo judicial do Supremo Tribunal Federal, para proteger a vida da mulher, bem como seu direito de autodeterminação.

O PL 8116/2014 contém 14 artigos que tratam desde o conceito de "nascituro" até seus direitos de ampla proteção jurídica por parte do Estado e da família. O PL 478/2007 traz como justificativa para a criação de um estatuto a necessidade de resguardar a expectativa de direitos aos que gozam de proteção mesmo sem ainda nascer, pois atualmente:

\footnotetext{
A proliferação de abusos com seres humanos não nascidos, incluindo a manipulação, o congelamento, o descarte e o comércio de embriões humanos, a condenação de bebês à morte por causa de deficiências físicas ou por causa de crime cometido por seus pais, os planos de que bebês
} 
sejam clonados e mortos com o único fim de serem suas células transplantadas para adultos doentes, tudo isso requer que, a exemplo de outros países como a Itália, seja promulgada uma lei que ponha um "basta" a tamanhas atrocidades (PL 478/2007, pg. 07, 2007).

Por fim, o último projeto de lei a ser tratado aqui é o 5166/2005 do deputado Takayama, um dos mais atuantes na bancada evangélica no que diz respeito à defesa da moral e dos bons costumes cristãos. Esta proposta discute o direito da mulher de abortar nos casos de anencefálico ou inviável. Segundo o autor, seria crime interromper a gravidez mesmo nestes casos haja vista que o feto anômalo é uma vida humana e deve ser tutelada pelo Estado como tal. Justifica, ainda, que "o determinismo biológico faz com que a mulher seja a portadora de uma nova vida, não é desejo, portanto, de nosso Bendito Criador que a porção feminina de sua obra aborte ou antecipe o parto mediante alguma intervenção cirúrgica" (PL 5166/2005, pg. 03, 2005).

Na contramão desta teoria, em 2012 o Tribunal Pleno do Supremo, por maioria e nos termos do voto do Relator, julgou procedente a ADPF 54 no sentido de declarar a inconstitucionalidade da interpretação segundo a qual a interrupção da gravidez de feto anencefálico seria crime tipificado nos artigos 124,126, 128, incisos I e II, do Código Penal. O Ministro Marco Aurélio Mello votou no sentido de descriminalizar o aborto nesses casos justificando que o feto sem cérebro, mesmo que biologicamente vivo, seria juridicamente morto, isto é, não teria proteção jurídico-penal. "Nesse contexto, a interrupção da gestação de feto anencefálico não configura crime contra a vida - revela-se conduta atípica" (STF, 2012, pg. 24) pois não existe vida possível capaz de criminalizar a conduta da mulher ou do médico de abortar. Mais recentemente, em 2016, o Supremo Tribunal Federal ${ }^{6}$ considerou, em decisão histórica da $1^{\text {a }}$ Turma, inconstitucionais os artigos do Código Penal que criminalizam o aborto, eis que, segundo o voto do Relator, o Ministro Luiz Roberto Barroso ${ }^{7}$, a criminalização do aborto até o terceiro mês de gestação conferiria uma proteção deficiente do Estado aos direitos sexuais e reprodutivos, à autonomia, à integridade psíquica e física, e à saúde da mulher, com reflexos sobre a igualdade de gênero e impacto desproporcional sobre as mulheres mais pobres.

Nesse sentido, pergunta-se: Qual vida proteger, do feto ou da mãe? Certamente há quem diga haver um aparente conflito de direitos. No entanto, se considerar-se a dignidade humana das mulheres e tomá-las como sujeitas dotadas de direitos e garantias fundamentais, bem como analisarmos todos os aspectos sociais de sua vida (casamento, trabalho, questões financeiras, etc), seu direito à autodeterminação em relação à reprodução, saúde e vida sexual, a resposta é: deve-se proteger a vida da mulher, bem como suas escolhas. O feminino não está mais submetido à vontade do masculino ou de uma doutrina religiosa. Se a todos são assegurados a liberdade e a igualdade, mulheres não devem ser tratadas de forma diferente e, pior, serem criminalizadas por isso.

Além disso, deve-se ressaltar que a cultura do abandono (literal e afetivo) paterno já

6 O marco dos direitos humanos é um componente essencial na defesa do direito ao aborto. Recentemente, e a partir da constatação da dificuldade para o avanço do direito ao aborto através dos órgãos políticos, organizações feministas na América Latina têm apelado às cortes nacionais, e em particular às cortes constitucionais. Em realidade, $\mathrm{o}$ desenvolvimento das demandas pela legalização do aborto na América Latina nas duas últimas décadas coincidiu com o desenvolvimento da justiça constitucional e a judicialização dos processos políticos, a partir especialmente da criação ou reforma de cortes constitucionais e cortes supremas com poder de controle de constitucionalidade em última instância. As cortes constitucionais tiveram um papel central, e suas decisões na maioria desses casos têm se referido à perspectiva dos direitos humanos das mulheres, e têm retomado alguns dos argumentos desenvolvidos por organizações feministas em cada caso. Em contextos caracterizados pela incidência de atores fundamentalistas nos poderes políticos do Estado, as Cortes Constitucionais têm demonstrado serem espaços institucionais mais isolados dessa influência, e com ânimo para defender a laicidade em seus processos decisórios (RUIBAL, 2014, pg. 126/127).

7 http://www.stf.jus.br/portal/cms/verNoticiaDetalhe.asp?idConteudo=330769 
tomou um status de "normalidade" no Brasil, visto socialmente a mãe, geradora, é que deve ter a responsabilidade de criação, não havendo qualquer criminalização ou punição ao homem que abandona seus filhos. Neste sentido, segundo o Conselho Nacional de Justiça, mais de 5,5 milhões de crianças não tem o nome do pai na certidão de nascimento ${ }^{8}$. Ou seja, os parlamentares que apresentam estes projetos defendem que a mulher não pode ter o direito de abortar já que o embrião é um ser vivo e, por este motivo, tem plenos direitos e deve ter proteção absoluta do Estado contra a subversão feminina de contrariar uma regra moral religiosa (RUIBAL, 2014), mas não se preocupam com o abandono paterno que pode gerar traumas na criança. $\mathrm{Ou}$, quando tentam se preocupar, colocam a mulher violentada em uma situação ainda mais vulnerável ao permitir que o estuprador tenha direitos paternos.

\subsection{Criminalizar já!}

Neste tópico analisaremos os projetos de lei que tratam da criminalização do aborto e do endurecimento das penas já previstas pela legislação brasileira para esse tipo. Para tanto, trataremos dos projetos de lei do Senado $n^{\circ}$ 460 e 461/2016 e projetos de lei no 5069/2013, 1545/2011 e 7443/2006, da Câmara dos Deputados. Os projetos de lei do Senado no 460 e 461, foram apresentados no ano de 2016 pelo Senador Pastor Valadares ${ }^{9}$ (Sebastião Valadares Neto), presidente da Convenção das Assembleias de Deus em Rondônia, Ministério de Madureira e também um dos apresentadores do programa evangélico Deus Fala Comigo, exibido em seu estado $^{10}$. O projeto 460 visa alterar o Código Penal para criminalizar o induzimento e a instigação ao aborto e o anúncio de meio abortivo (pílula do dia seguinte, por exemplo) bem como quer exigir o exame de corpo de delito e a prévia comunicação à autoridade policial para a mulher que aborta no caso de gravidez resultante de estupro. A imposição do exame vai de encontro a todas as políticas de resguardo e implementação de direitos humanos das mulheres, violando, sobremaneira, os direitos fundamentais (sexuais e reprodutivos), legitimando a violência de gênero.

$\mathrm{O}$ fato de impor à mulher tal procedimento primeiro desacredita sua palavra e, segundo, a faz passar por um processo doloroso e traumático, logo após uma experiência horrenda de violência contra seu corpo. Este exemplo só atesta a perspectiva subalterna que o projeto coloca na mulher. Spivak, em seu livro "Pode o subalterno falar?" (2010) questiona: “O que a elite deve fazer para estar atenta à construção contínua do subalterno? A questão da mulher parece ser a mais problemática nesse contexto. Evidentemente, se você é pobre, negra e mulher, está envolvida de três maneiras" (pg. 65) e, especificamente neste caso do aborto essas mulheres de classe baixa e negras são as mais prejudicadas por estes projetos. Primeiro porque mulheres com condição financeira que tiverem sofrido violência sexual e desta resultar uma gravidez, irão procurar atendimento particular (como acontece hoje) para abortar. No entanto, as mulheres desprovidas dessa condição, serão obrigadas a submeterem-se, nos hospitais públicos, a este exame que pode demorar dias, semanas ou até meses e, enquanto isso, ela deverá arcar com os custos e infortúnios dessa gravidez forçada.

O projeto ainda propõe alterações na Lei 12.845/13 que prevê o uso da chamada "pílula do dia seguinte" ("profilaxia da gravidez") às vítimas de abuso sexual, de acordo com a redação do artigo $3^{\circ}$, inciso IV do diploma normativo. Se o projeto de lei for aprovado definitivamente, a 
pílula só poderá ser utilizada pelos profissionais de saúde como medicação não abortiva para prevenir a gravidez resultante do estupro (MAIA SILVA; SOUZA, 2017). Dessa forma, o próprio conceito de violência sexual apresentado pela Lei $12.845 / 13$, que atualmente compreende qualquer forma de atividade sexual não consentida, independente da prática de violência, será alterado para abranger apenas o "crime contra a liberdade sexual de que resulte danos físicos e psicológicos".

Já o Projeto 461 também altera a legislação penal com o intuito de criminalizar a prática do aborto em qualquer estágio da gestação, sendo uma resposta clara e direta à decisão do STF que, ao julgar o HC 124.306/RJ, entendeu que a interrupção voluntária da gestação, efetivada nos primeiros três meses de gravidez deve ser excluída do âmbito de incidência dos artigos 124 a 126 do Código Penal (CP), que tratam do aborto. Outros dois projetos que tratam do assunto e são de autoria do ex-deputado Eduardo Cunha, são as proposições 1545/2011 e 7443/2006. O primeiro tipifica o crime de aborto praticado por médico quando não forem os 02 previstos no Código Penal: necessário (para salvaguardar a vida da gestante) ou de gravidez resultante de estupro (sentimental). A pena mínima passaria de 02 para 06 anos, enquanto a máxima dobraria de 10 para 20 anos de reclusão. Além disso, os médicos também seriam punidos com a proibição definitiva do exercício da profissão.

Já o projeto 7443/2006 tinha o intuito de incluir o tipo penal do aborto no rol de crimes hediondos, justificando que qualquer ato contra a vida deveria ser punido pelo Estado com o mais extremo vigor. Este, apesar de ter sido arquivado em 2007, foi desarquivado em 2015 (coincidentemente no momento em que o autor era presidente da casa) e atualmente tramita em conjunto com outros projetos de mesmo teor. As motivações destes projetos são praticamente as mesmas: proteção à vida humana intrauterina em qualquer dos seus estágios de desenvolvimento. Sendo assim, a intenção deste legislador é impedir a interrupção intencional e desmotivada do processo de gestação e, consequentemente, a morte dos sempre indefesos e vulneráveis fetos (PL 460/2016). Ademais, justifica ainda que muitas mulheres que abordam não tinham tal intenção, mas o fazem induzidas por seus companheiros ou médicos (PL 1545/2011). Neste sentido, estes projetos também seriam uma forma de proteger a vida da mulher destes "personagens ocultos que incentivam a interrupção da gestação e não são responsabilizados por falta de previsão legal" (PL 460/2016, pg. 03, 2016). O PL 7443/2006 ainda usa como justificativa a comparação do impacto e gravidade do aborto com os crimes de homicídio e estupro e propõe a inserção da interrupção voluntária da gravidez no rol dos crimes hediondos.

Por fim, o Projeto de Lei 5069/2013, de autoria de 14 Deputados Federais, dentre eles Eduardo Cunha ${ }^{11}$, Arolde de Oliveira, Lincoln Portela, João Campos, Roberto de Lucena e Marcos Rogério (todos integrantes da bancada evangélica), atua na mesma linha do projeto 460/2016 do Pastor Valadares, criminalizando o uso ou até mesmo a instrução e orientação sobre substâncias abortivas (como a pílula do dia seguinte), com penas máximas de até 10 anos, dependendo da situação do agente. Tais proposições, desde a criação, têm sofrido diversas críticas de movimentos feministas por obstarem a interrupção da gravidez em casos de violência sexual, além de criminalizá-la com mais rigor. Este projeto adiciona uma nova tipificação criminal ao Código Penal (artigo 127-A), definindo como delito o induzimento a instigação ou auxílio ao aborto. Além disso, ainda será criminalizada a conduta de entregar, mesmo que gratuitamente, substância ou objeto destinados a provocar aborto, bem como orientar e instruir a gestante sobre formas de se praticar aborto. Ainda, o delito se qualificará se o aborto 
for praticado por agente de serviço público de saúde ou por quem exerce a profissão de médico, farmacêutico ou enfermeiro.

Não bastasse isso, o projeto ainda possibilita ao médico de escusar-se ao dever de aconselhar, receitar ou administrar qualquer procedimento ou medicamento que provoque abortamento, de acordo com o exercício de seu "direito de consciência". Contudo, devemos salientar que essa previsão contraria o Código de Ética Médica, que apesar de garantir ao médico o direito de objeção de consciência, impõe o dever de orientar a vítima e garantir a atenção ao abortamento por outro profissional ou instituição (MAIA SILVA; SOUZA, 2017). REIS (2015), dissertando sobre os impactos do projeto 5069/2013 que trata dos Direitos das Mulheres, afirma que o efeito da não obrigatoriedade do médico em aconselhar, receitar ou administrar qualquer procedimento ou medicamento que provoque abortamento, faz com que as vítimas dependam do fator sorte, de modo que, quando do atendimento, se o médico possuir convicções severas, não poderá a vítima contar com a medicação ${ }^{12}$. Assim, vê-se claramentea inconstitucionalidade dodispositivo, já que, em razão da laicidade do Estado, não pode uma vítima ficar na dependência de convicção pessoal do profissional da saúde (MAIA SILVA; SOUZA, 2017).

Devemos destacar que essa proposição, já aprovada na Comissão de Constituição, Justiça e Cidadania da Câmara dos Deputados, prejudica a informação e o atendimento da vítima de violência sexual, impõe a vitimização secundária da mulher estuprada e, ainda, aumenta as chances de gravidez indesejada, eliminado a profilaxia da gravidez. Aliás, insta salientar que uma das estratégias utilizadas pelos grupos conservadores tem sido inserir seus membros em comissões legislativas essenciais para aprovar (ou rejeitar) qualquer projeto de lei que passe pela casa $^{13}$. A justificativa deste projeto começa com a explicação de que a legalização do aborto estaria sendo imposta por organizações internacionais que defendem a ideologia neo-maltusiana de controle populacional e financiadas por fundações norte-americanas ligadas a interesses supercapitalistas. Dessa maneira, os Estados Unidos estariam, desde a década de 70 , encorajando a prática do aborto em países subdesenvolvidos conseguindo enganar até mesmo as mulheres fazendo-as acreditar que a interrupção da gravidez seria uma "emancipação feminina" ou "meio de afirmação dos direitos sexuais e reprodutivos femininos", mas seu real objetivo nada mais é do que o controle demográfico da população mundial (PL 5069/2013).

Assim, é dever do sistema jurídico brasileiro enfrentar essa ofensiva internacional e fazer valer as normas constitucionais que protegem a inviolabilidade do Direito à vida e, para tanto, é importante o preenchimento de possíveis lacunas no sistema jurídico que ameaçam os direitos dos nascituros. E, finalmente, os deputados ainda afirmaram que as normas contrárias à interrupção voluntária da gravidez são "um desejo da maioria esmagadora do povo brasileiro, que repudia a prática do aborto, conforme verificado pelas mais

12 Este dispositivo segue a ideia da legislação italiana que legalizou o aborto em 1978, pela lei 194, permitindo a interrupção da gravidez nos primeiros 90 dias após a concepção, para proteger a saúde da mulher. Entretanto, a legislação ainda possibilita ao médico objetar-se de tal prática por justificativa de crença pessoal, fator que aumentou o número de abortos ilegais, pois a maioria dos médicos credenciados na rede pública negavam-se ao procedimento justificando sua doutrina religiosa cristã.

13 Em conjunturas importantes, a bancada religiosa tem presidido duas das comissões legislativas fundamentais para o tratamento do direito ao aborto: a Comissão de Seguridade Social e Família e a Comissão de Constituição, Cidadania e Justiça, ambas na Câmara dos Deputados (Mori, 2009, p. 83). Não obstante, o caso mais grave até o momento, quanto à inserção do fundamentalismo religioso no Estado, foi a eleição, em fevereiro de, 2013 como presidente da Comissão de Direitos Humanos e Minorias do deputado e pastor Marco Feliciano, que havia realizado manifestações públicas de conteúdo racista e abertamente contrárias aos direitos das mulheres e das minorias sexuais. Feliciano presidiu a Comissão até dezembro de 2013 e gerou uma advertência a outros setores da sociedade sobre a vulneração dos limites da esfera estatal por parte de atores fundamentalistas (RUIBAL, 2014, pg. 124). 
diversas pesquisas de opinião" (PL 5069/2013, pg. 06). E, sendo o Congresso Nacional responsável por traduzir a voz do povo brasileiro, a reforma legislativa que trata deste assunto é necessária para endurecer as penas e combater os meios que facilitam o aborto ilegal.

\section{CONCLUSÃO}

Questões sobre sexo e sexualidade sempre estiveram presentes em discussões na maioria das sociedades e "isso tem sido um elemento chave do debate político na maior parte dos dois últimos séculos" (WEEKS, 2007, pg. 73). Debate, pois, no que concerne ao tema, temos, de um lado, uma direita conservadora forte e numerosa, muitas vezes ligadas à alguma doutrina religiosa que julga o tópico através de sua moral própria e, por outro lado, defensores da igualdade de direitos e garantias em um Estado Democrático de Direito. As mulheres, apesar de constituírem $51,6 \%$ da população brasileira ${ }^{14}$, praticamente não têm voz na vida pública, tendo míseros 9\% de presença na Câmara dos Deputados (45 deputadas entre 513) e 13\% de Senadoras (sendo 10 entre 81 Senadores) ${ }^{15}$. E, esta falta de representatividade talvez seja um dos principais motivos que possibilitam a criação de projetos de leis controversos que tratem da saúde, segurança, liberdade sexual e reprodutiva da mulher, leis estas que, além de atestarem a ideia de que os homens "precisam tomar conta das mulheres" ainda retiraram direitos fundamentais já garantidos pela Corte Suprema e por nossa Constituição Federal.

Assim, tão antigo quanto o tema é a polêmica que o rodeia e, volta e meia, nos dias de hoje, somos testemunhas das tentativas de impedir a definitiva legalização de questões já legitimadas pelos tribunais superiores brasileiros. Um desses grupos que vem atuando na arena política brasileira é a Bancada Evangélica. A Frente
Parlamentar Evangélica vem ganhando cada vez mais espaço por suas ideias de defesa da moral e dos bons costumes da família tradicional brasileira, contrariando minorias e propondo leis que retirem ou dificultem direitos já garantidos, principalmente às mulheres e aos homossexuais. Este grupo demonstra o contexto político de interferência cada vez maior de moral religiosa na elaboração de normas penais e civis no Brasil, o que iria de encontro aos limites constitucionais impostos ao poder configurador do legislador e do próprio ideal de Estado Laico e Secular.

Rubin (1989) acertou ao questionar a legislação sexual em relação à normas sobre outras questões sociais. Neste sentido, a autora dirá que o Estado sempre interfere nas questões sexuais de um jeito que não seria tolerado em qualquer outro aspecto da vida social. E, na maioria das vezes essa intromissão é negativa no sentido de suprimir direitos simplesmente por entender que certas atitudes são imorais e contrariam os bons costumes da sociedade. Então, diante deste cenário, os legisladores evangélicos utilizam o ordenamento jurídico como uma vantagem na guerra contra os direitos homoafetivos e sexuais femininos, demonstrando a falta de preocupação em realmente preservar a vida.

Após a exposição destas nove proposições legislativas que tratam sobre o direito à vida $\mathrm{e}$ interrupção voluntária da gravidez, algumas considerações podem ser feitas quanto ao discurso dos parlamentares para justificar seu posicionamento "pró-vida" e contra o aborto. Apesar de a premissa de natureza confessional ser ainda muito forte nas falas em plenários e entrevistas dos parlamentares da bancada evangélica, percebe-se que nestes projetos os argumentos religiosos foram usados com cautela e geralmente serviram apenas para reafirmar um outro argumento de natureza diversa. Isto ocorre provavelmente pois vários projetos de leis anteriores foram rejeitados logo no início de sua

14 http://www.brasil.gov.br/cidadania-e-justica/2015/03/mulheres-sao-maioria-da-populacao-e-ocupam-mais-espacono-mercado-de-trabalho

15 http://politica.estadao.com.br/noticias/geral,brasil-tem-menos-mulheres-no-legislativo-que-oriente-medio,1645699 
tramitação sob a justificativa de contrariarem a laicidade, já que as proposições sobre criminalização do aborto praticamente possuíam apenas justificativas religiosas ("Desejo de Deus", "Está escrito na Bíblia”, "Criador concedeu a vida, só ele tem o poder de tirá-la”, dentre outros). Portanto, para conseguir que os projetos continuassem até a votação em plenário, motivos científicos e sociais foram adicionados junto aos religiosos, como veremos adiante.

Dois motivos presentes em quase todos os projetos apresentados são "a defesa da família tradicional" e "a defesa incondicional da vida em qualquer estágio”. Ambos são reconhecidos como valores morais cristãos pois baseiamse principalmente nas escrituras sagradas. Para as mulheres o sexo deve ser considerado estritamente com fim único de reprodução (e não, também, o prazer) e isto justifica a visão religiosa contrária ao aborto. A relação sexual geralmente é considerada como perigosa, destrutiva, uma força negativa (RUBIN, 1986), sendo "tolerável” apenas para um bem maior, qual seja, a procriação. E, em sendo assim, toda e qualquer gravidez será "desejada", "planejada e "sabida" (portanto, desnecessário o aborto) pois a função feminina é gerenciar as relações com afeto e emoção. Neste sentido, Altivo, comentando a visão da Igreja Universal sobre casamento e o papel da mulher, dissertará que à mulher cabe "atuar na constituição de pessoas (pela maternidade e pelos cuidados com a manutenção dos corpos familiares) nas relações de afeto e emoção que configuram o ambiente acolhedor do lar" (2016, pg. 182).

O determinismo biológico também foi utilizado como fundamento nos projetos. Este pressupõe que as características físicas e psicológicas das mulheres a obrigam a ser mãe, mas isto não a permite escolher sobre a vida/ morte do bebê, cabendo a Deus tal decisão. Por esta premissa também se explica outro argumento: o da fragilidade das mulheres. Eduardo Cunha, em um dos seus projetos, alega que as mulheres precisam de proteção de seus companheiros e médicos que as induzem ao aborto. Outra premissa comum nas proposições é a comparação do aborto com homicídio. Muitos deputados defendem que a interrupção voluntária da gravidez deve ter suas penas endurecidas pois uma vida indefesa está sendo ceifada, neste sentido, é necessário não só criminalizar, mas também incluir o aborto no rol de crimes hediondos para que aquelas que cometam tal prática não sejam beneficiadas pelas leis de processo penal.

Finalmente, dentre os argumentos mais utilizados, não poderia deixar de destacar aquele que se baseia no "desejo da maioria da população". Os parlamentares justificam ser o aborto ilegal pois grande parte dos brasileiros, que seriam cristãos, são contrários a tal prática e, sendo as leis fenômenos sociais, cabe aos Deputados e Senadores ouvirem o clamor das ruas e criarem as leis baseando-se na moral e princípios que grande parte tem como certo. Porém dentre os argumentos apresentados, o que mais preocupa é aquele que trata sobre o ativismo judicial do STF. O sistema de freios e contrapesos e a tripartição dos poderes é um dos principais fundamentos de uma república democrática, devendo as três esferas agirem harmonicamente. Cada um têm o seu papel a desempenhar perante a sociedade. No entanto, para que a população não saia prejudicada no caso de negligência de uma dessas esferas, a própria carta magna trouxe previsões da possibilidade de um poder agir numa função típica de outro.

O Supremo Tribunal Federal, ao ter uma postura pró-ativa em alguns assuntos (sempre após ser provocado de maneira legal e na forma prevista) está assegurando que minorias tenham seus direitos garantidos a despeito de ainda não haver qualquer lei tratando sobre a matéria. Quando a Corte Suprema legitima o casamento entre pessoas do mesmo sexo e permite que uma mulher interrompa a gravidez, ela não está legislando, mas sim fazendo valer os direitos e garantias fundamentais previstos no artigo $5^{\circ} \mathrm{da}$ Constituição. E, diante da realidade brasileira e da crescente onda conservadora na política, os cidadãos precisam sempre ter a quem e como 
recorrer na defesa dos seus direitos. Por isso instituições e indivíduos estão preocupados com o fato de vários parlamentares (não só da bancada evangélica) apresentarem projetos para limitar ou até mesmo anular essa prática recorrente. Caso isso ocorra, vários grupos perderam a única via legal que têm hoje para assegurar uma efetiva isonomia social.

Ademais, devemos destacar que estes projetos, caso aprovados, serão ineficientes para diminuir o número de interrupções voluntárias da gravidez (e mortes em decorrência de procedimentos inadequados) pois muitas mulheres continuarão praticando o aborto, algumas em clínicas particulares e outras buscando formas alternativas, perigosas e inseguras para o fim da gestação. Infelizmente, ao invés de os congressistas preocuparem-se em regulamentar o aborto e dar condições médicas, psicológicas e seguras para as mulheres prevenirem a gravidez ou abortarem, eles operam com uma racionalidade de morte e não de proteção a vida, já que a "ampliação dos tipos penais e a minimização da política de redução de danos prevista na lei de atendimento integral às vítimas de violência sexual revelam um ódio à autonomia sexual e reprodutiva das mulheres que beira à misoginia”. (CAMPOS, AMORIM; LOYOLA, 2013, pg. 18)

Assim, os dispositivos não servem ao ideal de proteção da vida, mas sim, "ao controle sexual e reprodutivo das mulheres, demonstrando a hipocrisia do discurso em defesa da vida" (CAMPOS, AMORIM; LOYOLA, 2013, pg. 19), ademais, projetos de leis com esse conteúdo e justificativa estritamente moral, só atestam a ideia de submissão feminina, dessa vez, à vontade de um legislador que, ao tentar impor sua doutrina religiosa, ameaça direitos humanos, sexuais e reprodutivos das mulheres, além de contrariarem o princípio da laicidade estatal. Isto explica porquê organizações internacionais, como o Comitê de Direitos Humanos da ONU ${ }^{16}$ e a Anistia Internacional ${ }^{17}$ demonstraram preocupações acerca do retrocesso de direitos que vem ocorrendo no Brasil desde a saída da Presidenta Dilma, em 2015. São quase 200 propostas diferentes de emendas constitucionais, novas leis e modificações da legislação existente que ameaçam uma série de direitos humanos, Entre essas medidas retrógradas estão: redução da maioridade penal, revogação do estatuto do desarmamento, proibição absoluta do aborto (violando os direitos sexuais e reprodutivos das mulheres e meninas) e restrição ao direito de manifestação pacífica (ANISTIA, 2018). Por conseguinte, discussões como a proposta neste trabalho são importantes para que a população tome conhecimento das agendas dos políticos e de suas propostas.

\section{AGRADECIMENTOS}

Agradeço à Fundação de Amparo à Pesquisa do Estado de Goiás (FAPEG) pelo auxílio financeiro que possibilitou o Doutorado Sanduíche na Università di Pisa, bem como a realização desta pesquisa.

\section{REFERÊNCIAS BIBLIOGRÁFICAS}

ALTIVO, Bárbara. Dever e prazer no casamentoempresa: transações regulares de controle do amor segundo a Igreja Universal. In: Revista Galáxia Online, n. 32, 2016, pg. 176-187.

ANISTIA INTERNACIONAL. O Estado dos Direitos Humanos no Mundo: Informe 2017/2018. Disponível em: https://anistia.org.br/wp-content/ uploads/2018/02/informe2017-18-online1.pdf Acesso em: 14/06/2018.

BERGER, Peter. A dessecularização do Mundo: uma visão global. In: Religião \& Sociedade. Rio 
de Janeiro, 2011, pg. 09-23.

BOBBIO, Norberto. A era dos Direitos. Trad.: Nelson Coutinho, Rio de Janeiro: Elsevier, 2004.

BRASIL. Constituição da República Federativa do Brasil. São Paulo: Saraiva, 2017.

Lei 12.835/13. Disponível para acesso em: http://www.planalto.gov.br/ccivil 03/ ato2011-2014/2013/lei/112845.htm Acesso em $10 / 05 / 2017$.

BUTLER, Judith e RUBIN, Gayle. "Tráfico sexual - entrevista (Gayle Rubin com Judith Butler)”. In: Cadernos Pagu (21). Campinas: Núcleo de Estudos de Gênero Pagu/Unicamp, 2003.

CÂMARA DOS DEPUTADOS, Frente Parlamentar Evangélica. Disponível para acesso em: http://www.camara.leg.br/internet/ deputado/frenteDetalhe.asp?id=53658 Acesso em 15/05/2018.

PL 478/2007. Disponível para acesso em: http://www.camara.gov.br/proposicoesWeb/ fichadetramitacao?idProposicao $=345103$ Acesso em 15/05/2018.

PL 1.545/2011. Disponível para acesso em: http://www.camara. gov.br/proposicoes Web/prop egra? codteor $=884992 \&$ filename $=P L+1545 / 2011$ Acesso em 15/05/2018.

PL 5.069/13. Disponível para acesso em: http://www.camara.gov.br/proposicoesWeb/ fichadetramitacao?idProposicao $=565882$ Acesso em 15/05/2018.

PL 5166/2005. Disponível para acesso em: http://www.camara. gov.br/proposicoes Web/prop egra? codteor $=304198 \&$ filename $=\mathrm{PL}+5166 / 2005$ Acesso em 15/05/2018.

. PL 6.583/2013. Disponível para acesso em: http://www.camara.gov.br/proposicoesWeb/ fichadetramitacao?idProposicao $=597005$ Acesso em 15/05/2018.

PL 7.443/2006. Disponível para acesso em: http://www.camara. gov.br/proposicoes Web/prop egra? codteor $=416204 \&$ filename $=\mathrm{PL}+7443 / 2006$ Acesso em 15/05/2018.

PL 8166/2014. Disponível para acesso em: http://www.camara.gov.br/proposicoesWeb/p a ? codteor $=1287642 \&$ filename $=P L+8116 / 2014$ Acesso em 15/05/2018.

CAMPOS Carmen Hein de; AMORIM, Rovena Furtado, LOYOLA, Júlia Roberta Teixeira; Aborto Análise crítica do PL 5069/2013. In: Revistas Eletrônicas PUC RS, Porto Alegre, 2013.

DEPARTAMENTO INTERSINDICAL DE ASSESSORIA PARLAMENTAR. Evangélicos crescem no Congresso; PSC tem mais representantes. Disponível para acesso em: http://www.diap.org.br/index.php?option=com content \&view $=$ article\&id $=14637$-evangelicoscrescem-no-congresso-psc-lidera-em-numerode-parlamentares Acesso em 15/05/2017

DINIZ, Madeiro Marcelo. Pesquisa Nacional de Aborto 2016. Cien Saude Colet [periódico na internet] (2016/Nov). disponível em: http://www.cienciaesaudecoletiva.com. br/artigos/pesquisa-nacional-de-aborto2016/15912?id=15912\&id=15912. Acesso em $07 / 05 / 2018$.

EXAME. Os números da violência contra mulheres no Brasil. In: Revista Exame: 08/03/2017. Disponível em: https://exame.abril. com.br/brasil/os-numeros-da-violencia-contramulheres-no-brasil/ Acesso em: 06/12/2017

FRANCHETTO, Bruna; CAVALCANTI, Maria Laura; HEILBORN, Maria Luiza. "Antropologia e Feminismo". In: Perspectivas Antropológicas da Mulher. Rio de Janeiro: Zahar Editores, 1980. 
LUNA, Naara. "Aborto no Congresso Nacional: $O$ Enfrentamento de atores religiosos e feministas em um Estado laico". In: Revista Brasileira de Ciência Política, ${ }^{\circ} 14$. Brasília, maio - agosto de 2014, pp. 83-109.

MACHADO, Maria das Dores Campos; BURITY, Joanildo. A Ascensão Política dos Pentecostais no Brasil na Avaliação de Líderes Religiosos. In: Revista de Ciências Sociais, Rio de Janeiro, vol. 57, no 3, 2014, pg. 601 a 631.

MAIA SILVA, Renata Cristina; SOUZA, Naiana Zaiden Rezende. Atuação da frente parlamentar evangélica frente aos direitos fundamentais das mulheres: projeto de lei do aborto e estatuto do nascituro. In: Revista Aporia Jurídica (online). Revista Jurídica do Curso de Direito da Faculdade CESCAGE. 8a Edição. Vol. 1 (jul/dez2017). p. 295 - 316.

NAÇÕES UNIDAS. Feminicídio: Brasil quinto maior do mundo. In: ONU: 12/04/2016. Disponível em: https://nacoesunidas.org/ onu-feminicidio-brasil-quinto-maior-mundodiretrizes-nacionais-buscam-solucao/ Acesso em: 06/12/2017.

RUBIN, Gayle. "El Tráfico de Mujeres: notas sobre la "economia política" del sexo". In: Revista Nueva Antropología (30, VIII). México: 1986.

SCHUCK, Elena de Oliveira. As políticas de gênero e o enfrentamento da bancada religiosa no Poder Legislativo. Disponível para acesso em: $\quad$ http://www.fg2013.wwc2017.eventos. dype.com.br/resources/anais/20/1373336040 ARQUIVO Schuck.FazendoGenero.pdf Acesso em 23/05/2018.

SENADO FEDERAL, PL 460/2016. Disponível para acesso em: https://www25.senado.leg. br/web/atividade/materias/-/materia/127777 Acesso em 25/05/2018.

PL 461/2016. Disponível para acesso

em: $\quad$ https://www25.senado.leg.br/web/ atividade/materias/-/materia/127776 Acesso em 25/05/2018.

SOFIATI, Flávio. "Perspectivas da laicidade no Brasil Contemporâneo". In: Dossiê Desafios Contemporâneos da Sociologia da Religião Cadernos, 2015, pg. 327 - 350.

SPIVAK, Gaiatry. Pode o subalterno falar? Belo Horizonte: Editora da UFMG, 2010.

SUPREMO TRIBUNAL FEDERAL, APFD 54.

Disponível para acesso em: http://www.stf.jus. br/portal/processo/verProcessoAndamento. asp?incidente $=2226954$ Acesso em 12/04/2018.

RUIBAL, Alba. "Feminismo frente à Fundamentalismos Religiosos". In: Revista Brasileira de Ciência Política, $\mathrm{n}^{\circ}$ 14, 2014, pg. $111-138$.

WEEKS, Jeffrey. "O corpo e a sexualidade". In: Louro, G. O Corpo Educado - pedagogias da sexualidade. Belo Horizonte: Autêntica, 2007. 